\title{
A Novel Bio-adsorbent of Mint Waste for Dyes Remediation in Aqueous Environments: Study and Modeling of Isotherms for Removal of Methylene Blue
}

\author{
TARIK AINANE*, FATIMA KHAMMOUR, MOHAMMED TALBI and M'HAMED ELKOUALI
}

\author{
Laboratory of Analytical Chemistry and Physical Chemistry of Materials, Faculty of \\ Sciences Ben Msik, Hassan II University, BP 7955 Casablanca - 20700, Morocco. \\ ${ }^{*}$ Corresponding author E-mail: ainane @ gmail.com
}

http://dx.doi.org/10.13005/ojc/300332

(Received: July 25, 2014; Accepted: September 09, 2014)

\begin{abstract}
The objective of this study was to investigate the possibility of using mint waste as a bioadsorbent for the removal of dye (Methylen Blue) from aqueous solutions. Batch adsorption studies were carried out by monitoring the $\mathrm{pH}$, the bio-adsorbent dose and the initial dye concentration. Attempts have also been made to monitor the adsorption process through Langmuir, Freundlich, Dubinin-Radushkevich, and Temkin adsorption isotherm models. These results have demonstrated the immense potential of mint waste as a bioadsorbent for dyes remediation in polluted water and wastewater. Finally followed by the process of adsorption phenomenon was achieved by fourier transform infrared spectrometer (FTIR), the results shows that the adsorption is mechanical trapping.
\end{abstract}

Keys words: removal of dyes, bio-adsorbent, waste mint, methylene blue, modeling, FTIR.

\section{INTRODUCTION}

Dyeing technology is synonymous to man's existence and the usage of dye products is unavoidable ${ }^{1-2}$. However, dyeing causes major problems when synthetic dyes are indiscriminately released into the environment producing pollution to man and his environment due to their slow biodegradability ${ }^{3}$. The contamination of water bodies by dyes has created serious environmental problems worldwide ${ }^{4}$.
In the other hand, large amounts of dyeing wastewater containing a certain amount of residual dye and a large number of dyeing auxiliaries are rich in harmful substances, and waters have different colors ${ }^{5}$. The presence of small amount of dyes is highly visible and undesirable. Whence, the necessity for dye-containing water to undergo treatment before disposal into the environment is highly imperative ${ }^{6-7}$.

Conventional wastewater treatment methods for removing dyes include physicochemical, chemical 
and biological methods, such as coagulation and flocculation, ozonation, electrochemical techniques, fungal decolorization and others techniques ${ }^{8-9}$. But these processes are not always effective and economic where the solute concentrations are very low. Besides, most of the dyes undergo very slow biodegradation. Actually, the sorption technique has been proven to be an effective and attractive process for the treatment of dye-containing wastewater ${ }^{10}$. In recent years, biosorption has been strongly recommended as an economically viable sustainable technology for the treatment of wastewater streams ${ }^{11}$. The importance and usefulness of biosorption in wastewater treatment is well established ${ }^{12}$. Biosorption in environmental engineering is now in the focus and consideration of all nations, owing to its low initial cost, simplicity of design, ease of operation, insensitivity to toxic substances and complete removal of pollutants even from dilute solutions ${ }^{13-14}$.

The equilibrium sorption isotherm is fundamentally important in the design of sorption systems. Equilibrium studies give the capacity of the sorbent and describe the sorption isotherm by constants whose values express the surface properties and affinity of the sorbent. Equilibrium relationships between sorbent and sorbate are described by sorption isotherms, usually the ratio between the quantity sorbed and that remaining in the solution at a fixed temperature at equilibrium ${ }^{15-16}$.

This study is to investigate sorption of methylene blue (MB) from aqueous solution using mint waste biomass. In order to understand the nature of the sorption: at first we conducted an optimization of the parameters of adsorption such as $\mathrm{pH}$ effect, mass effect and the effect of initial concentrations of $\mathrm{BM}$, and on the other hand kinetics and equilibrium isotherms have been evaluated. Also, we characterized mint waste biomass samples before and after MB adsorption by FTIR.

\section{MATERIALS AND METHODS}

\section{Materials}

The waste mint was collected from the waste cafeteria (University Hassan 2, Casablanca, Morocco). The collected materials were washed several times with boiled water and finally with distilled water to remove any adhering dirt. The washed materials were then dried in the oven at 60 $æ \% \mathrm{C}$ for $72 \mathrm{~h}$. The dried biomass was then ground and sieved to obtain the particle size in the range 250-500 $\mu \mathrm{m}$. Finally, the resulting product was stored in air-tight container for further use. No other chemical or physical treatments were applied prior to adsorption experiments.

\section{Chemicals}

Stock solution was prepared by dissolving $1.0 \mathrm{~g}$ of methyleneblue (MB) supplied by SigmaAldrich in $1 \mathrm{~L}$ distilled water. The test solutions were prepared by diluting stock solution to the desired concentrations. The maximum wavelength of this dye is $664 \mathrm{~nm}$.

\section{Effects of solution $\mathrm{pH}$, of adsorbent dosage and of initial concentration}

The effect of $\mathrm{pH}$ on the removal of $\mathrm{MB}$ was analyzed over the $\mathrm{pH}$ range 2-12. The $\mathrm{pH}$ was adjusted using $0.01 \mathrm{M} \mathrm{NaOH}$ and $0.01 \mathrm{M} \mathrm{HCl}$ solutions. In this study, $100 \mathrm{~mL}$ of dye solution with fixed initial concentration of $50 \mathrm{mg} / \mathrm{L}$ was taken in a stopperred conical flask and was agitated with 0.1 $\mathrm{g}$ of biomass for 2 hours.

The effect of biomass dose on the amount of $\mathrm{MB}$ adsorbed was obtained by contacting $100 \mathrm{~mL}$ of MB solution of initial concentration of $50 \mathrm{mg} / \mathrm{L}$ with different amount of biomass into a number of $250 \mathrm{~mL}$ stopperred glass Erlenmeyers flasks at temperature of $25^{\circ} \mathrm{C}$ and at $\mathrm{pH} 7.1$. Dye solutions were then analyzed thereafter at which equilibrium is assumed (2 hours).

A test of the effect of concentration was obtained by contacting $100 \mathrm{~mL}$ volumes of $\mathrm{MB}$ at concentrations of $10-50 \mathrm{mg} / \mathrm{L}$, with masses of 0.1 $\mathrm{g} / \mathrm{L}$ of the mint in Erlenmeyers flasks $250 \mathrm{~mL}$ at 25 ${ }^{\circ} \mathrm{C}$ and at $\mathrm{pH} 7.1$.

\section{Equilibrium studies and modelling}

Equilibrium studies were carried out by contacting fixed amount of biomass ( $1 \mathrm{~g} / \mathrm{L})$ with 100 $\mathrm{mL}$ of $\mathrm{MB}$ solution of different initial concentrations in $250 \mathrm{~mL}$ stopper conical flasks at a temperature of $25 \pm 2^{\circ} \mathrm{C}$ and $\mathrm{pH}$ of 7.13 . The initial and equilibrium concentrations of MB were analyzed using a UV-vis spectrophotometer (Shidmadzu Model UV-1601) at a wavelength of maximum absorbance $(664 \mathrm{~nm})$. The 
amount of adsorption at equilibrium, $\mathrm{q}_{\mathrm{e}}(\mathrm{mg} / \mathrm{g})$, was calculated by

$$
\mathrm{q}=\frac{\left(\mathrm{C}_{0}-\mathrm{C}_{\mathrm{e}}\right)}{\mathrm{W}}
$$

Where $\mathrm{C}_{0}$ and $\mathrm{Ce}(\mathrm{mg} / \mathrm{L})$ are the liquid phase concentrations of $\mathrm{MB}$ at initial and equilibrium, respectively. W $(\mathrm{g} / \mathrm{L})$ is the mass of biomass used in the volume of the solution. The percentage removal of dye was calculated as follows:

$$
\text { Removal percentage }=\left(\frac{\mathrm{C}_{0}-\mathrm{C}_{\mathrm{e}}}{\mathrm{C}_{0}}\right) \times 100
$$

To examine the relationship between absorbed and aqueous concentration at equilibrium, we used the theoretical models (two-parameter sorption isotherm models) that are shown in Table 1, such as: Freundlich ${ }^{17}$, Langmuir ${ }^{18}$, Dubinin Radushkevich ${ }^{19}$, Temkin ${ }^{20}$.

\section{Characterization}

Fourier transform infrared (FTIR) analysis was applied to determine the surface functional groups, using an FTIR spectroscope (Vertex 70), where the spectra were recorded from 4000 to 400 $\mathrm{cm}^{\prime \prime}$.

\section{RESULTS AND DISCUSSION}

\section{Effects of solution $\mathrm{pH}$, of adsorbent dosage and} of initial concentration

The effect of $\mathrm{pH}$ (Figure 1) was realized by initial concentration $\mathrm{C}_{0}=50 \mathrm{mg} / \mathrm{L}$, adsorbent dose $\mathrm{m}=1 \mathrm{~g} / \mathrm{L}$, and $\mathrm{pH}=2.4,4.7,7.1,9.8$ and 11.8. The removal percentages are respectively $68.49 \pm 7.43 \%, 89.47 \pm 2.75 \%, 90.32 \pm 1.81 \%$, $90.04 \pm 3.01 \%$ and $89.26 \pm 1.63 \%$. The results of this experiment show that the $\mathrm{pH}=7.1$ has a high removal percentage, hence the continuation of the all experiments of this work were that $\mathrm{pH}$.

On the other hand, the effect of adsorbent dose (Figure 2) was realized by initial concentration $\mathrm{C}_{0}=50 \mathrm{mg} / \mathrm{L}, \mathrm{pH}=7.1$ and adsorbent dose $\mathrm{m}=0.2$, $0.4,0.6,0.8$ and $1 \mathrm{~g} / \mathrm{L}$. The removal percentages are respectively $77.71 \pm 5.26 \%, 82.67 \pm 4.86 \%$, $87.59 \pm 4.94 \%, 90.30 \pm 3.47 \%$ and $91.31 \pm 3.35$ $\%$. The results show that the removal percentage is increased relative to the increase in dose of the adsorbent.

Finally, the effect of initial concentration (Figure 3) was realized by adsorbent dose $m=1 \mathrm{~g} / \mathrm{L}$, $\mathrm{pH}=7.1$ and initial concentration $\mathrm{C}_{0}=10,20,30$ and $40 \mathrm{mg} / \mathrm{L}$. The removal percentages are respectively $85.37 \pm 1.95 \%, 80.56 \pm 0.25 \%, 74.35 \pm 1.20 \%$ and $72.13 \pm 0.61 \%$. The results show that the removal percentage is increased relative to the decrease in the initial concentration.

Table 1: Two parameter sorption isotherm models

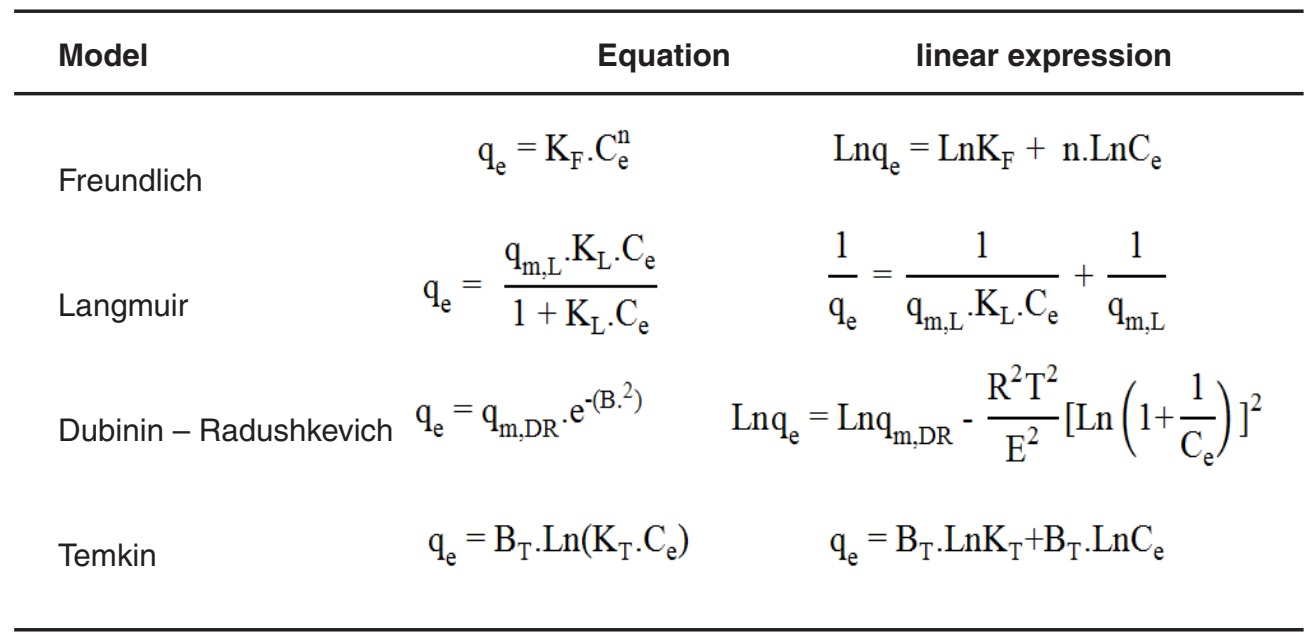




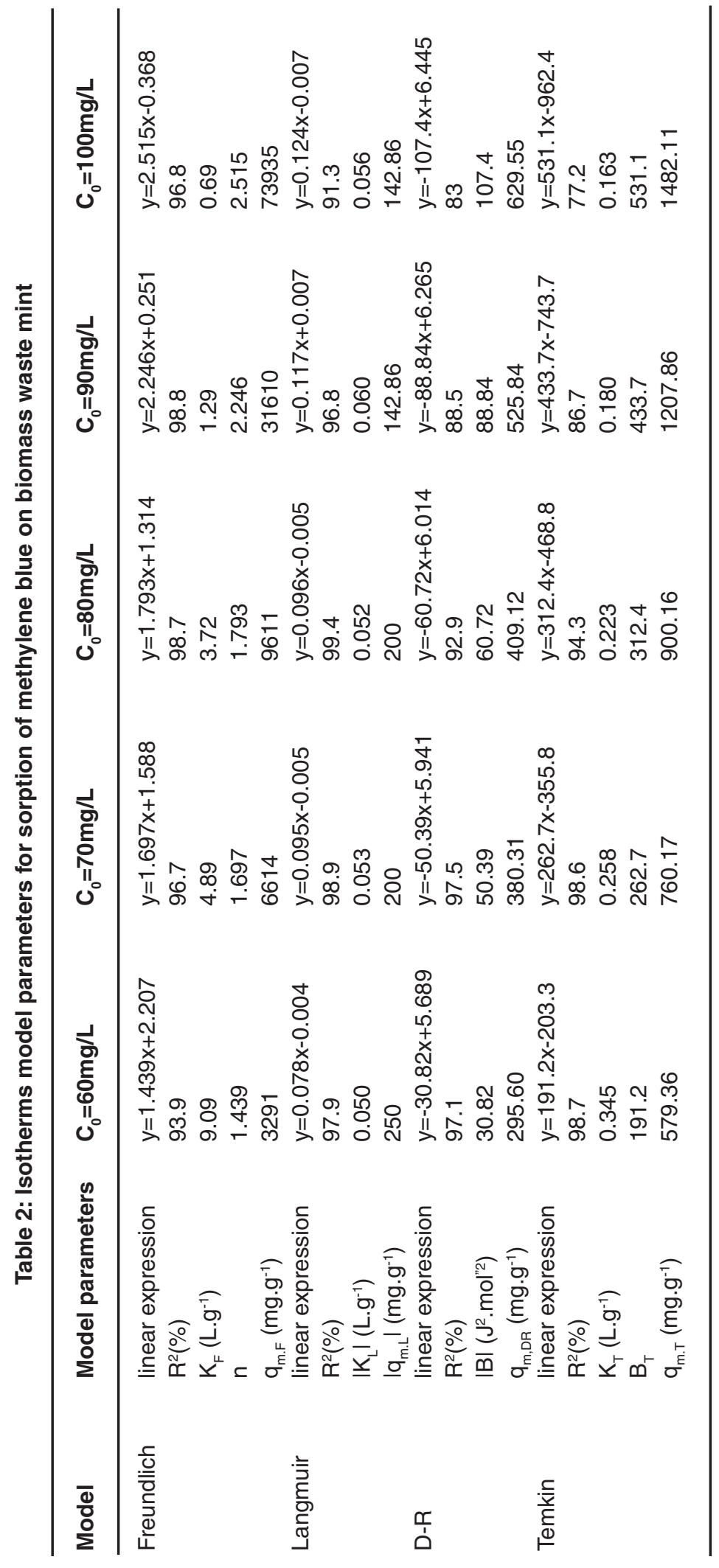


Equilibrium studies and modelling

The isotherms study of sorption of methylene blue was done during a time of two hours, with agitation, temperature $\mathrm{T}=25^{\circ} \mathrm{C}$ and $\mathrm{pH}=7.1$ constants. We tested initial concentrations: 60, 70, 80,90 and $100 \mathrm{mg} / \mathrm{L}$. Figure 4 illustrates the variation in the adsorption capacity $q$ versus at equilibrium

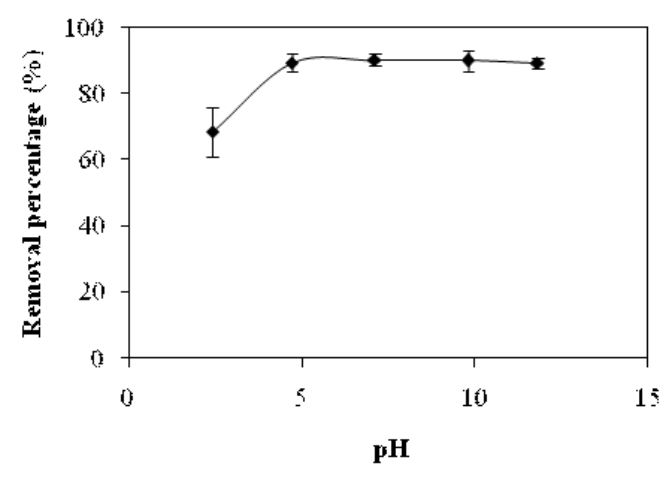

Fig. 1: Effect of pH

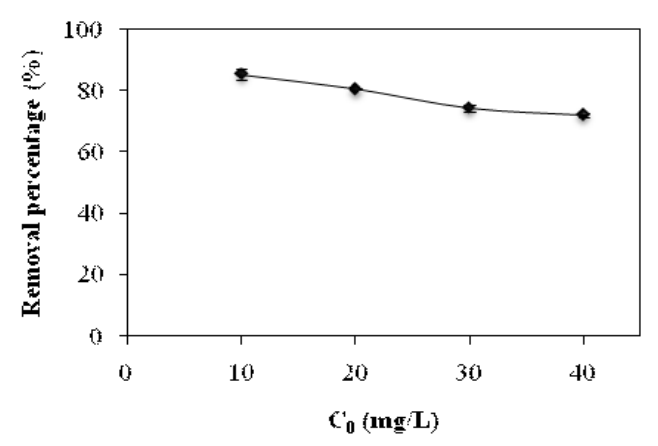

Fig. 3: Effect of initial concentration

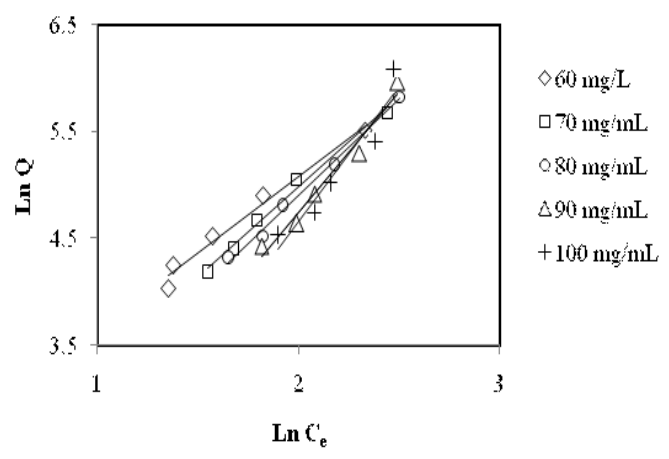

Fig. 5: Linear regression of the Freundlich model concentration $\mathrm{C}_{e}$. This curves obtained shows that the physicochemical process of absorption is interpreted difficult thing, and the explanation is unknown. For that, we tested the theoretical models that can give experimental approaches to demonstrate the real mechanism.

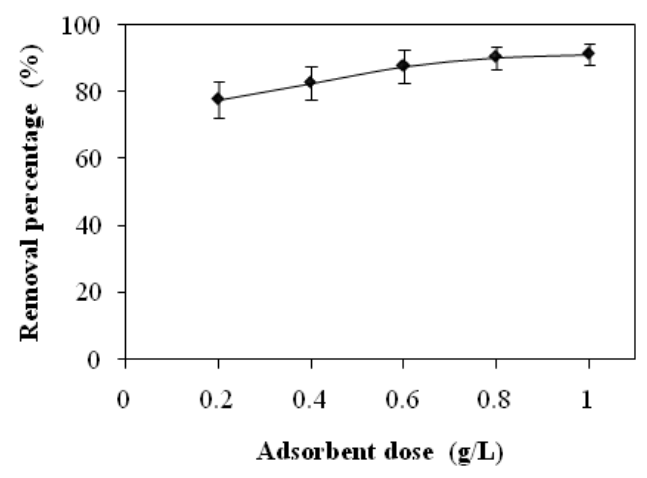

Fig. 2: Effect of adsorbent dose

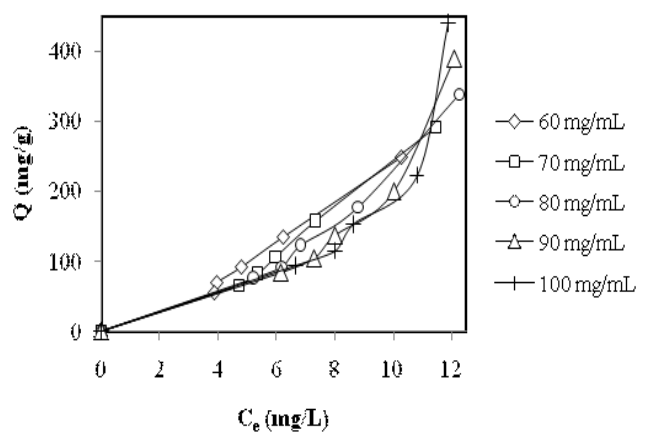

Fig. 4: Experimental adsorption isotherms

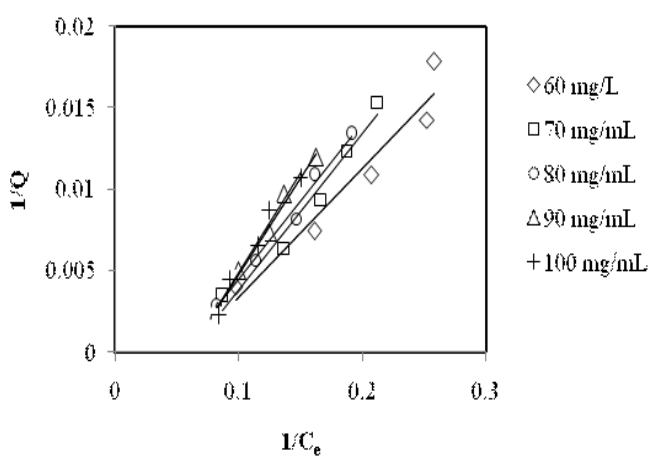

Fig. 6: Linear regression of the Langmuir model 


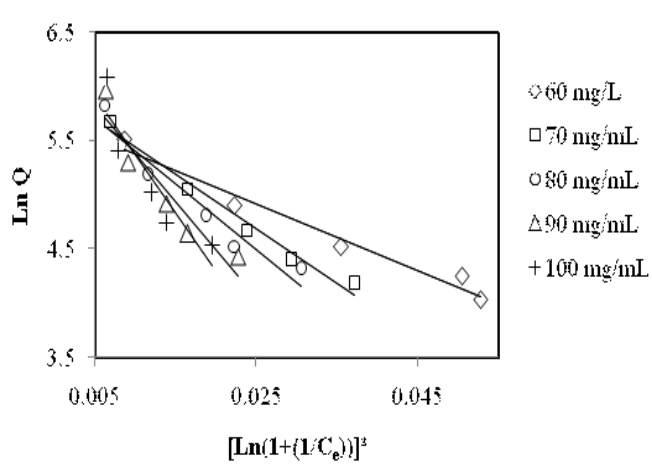

Fig. 7: Linear regression of the Dubinin - Radushkevich model

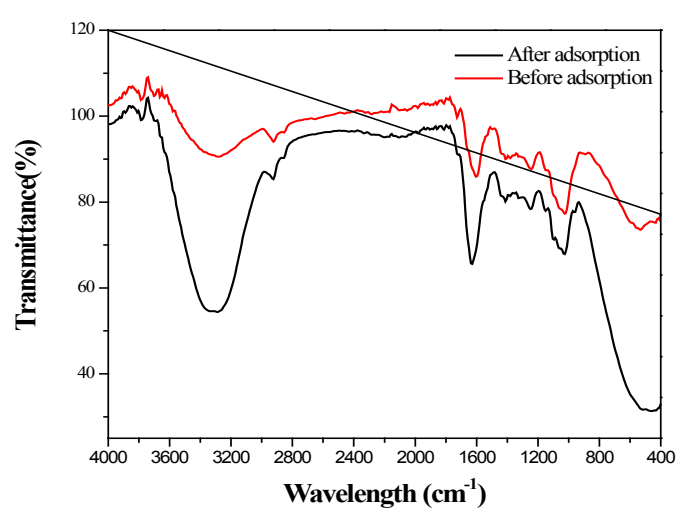

Fig. 9: FTIR spectra before and after adsorption methylene blue by bio-adsorbent

All the parameters of isotherms for sorption the methylene blue by biomass waste mint are determined from the straight linearity (Figure 5, 6, 7 and 8) according to the equations of the models described in Table 1. In considering the reliability of the proposed isotherms models, we calculated the correlation coefficients of the equations and the constants of each model. These are grouped in Table 2.

From the values of correlation coefficients $\mathrm{R}^{2}$ of these tables we can conclude that the model of Langmuir is closer to the experimental results of adsorption for initial concentrations: 60,70 and 80 $\mathrm{mg} / \mathrm{L}$, that correlation coefficients are respectively: $97.9 \%, 98.9 \%$ and $99.4 \%$, and the model of Freundlich is closer to the experimental results of

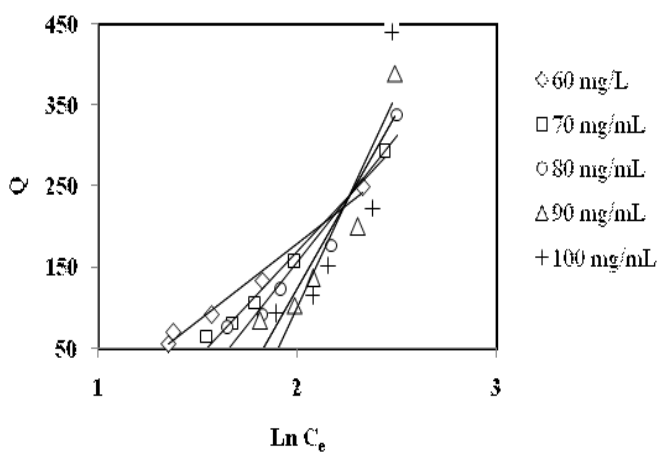

Fig. 8: Linear regression of the Temkin model

adsorption for initial concentrations: 90 and 100 $\mathrm{mg} / \mathrm{L}$, that correlation coefficients are respectively: $98.8 \%$ and $96.8 \%$. By cons, we note that the theoretical data from other models move away from the experimental data.

\section{FTIR interpretation}

The FTIR spectra before and after adsorption biomass methylene blue are shown in Figure 9. In the FTIR spectra of biomass before adsorption shows broad peaks and intense absorption at about $3443 \mathrm{~cm}^{-1}$ correspond to elongation of $\mathrm{OH}$, also, vibrations due to inter and intramolecular hydrogen bonding of polymeric compounds (macromolecular associations), such as alcohols, phenols and carboxylic acids, such as pectin, cellulose and lignin, thus showing the presence of hydroxyl groups "free" on the surface of the adsorbent. The peak at $2921 \mathrm{~cm}$ ${ }^{-1}$ is attributed to $\mathrm{CH}$ symmetric and asymmetric vibration aliphatic acid elongation. The peak at $1655 \mathrm{~cm}^{-1}$ is the asymmetric stretching vibration of $\mathrm{C}=\mathrm{O}$ and the peak observed at $1512 \mathrm{~cm}^{-1}$ be assigned to a group of aromatic compound. Other prominent peaks are the vibrations of $\mathrm{NH}_{2}, \mathrm{C}=\mathrm{O}$ and $-\mathrm{C}-\mathrm{C}-$ are respectively observed at 1440 $\mathrm{cm}^{-1}, 1066 \mathrm{~cm}^{-1}$ and $875 \mathrm{~cm}^{-1}$. Some distinct changes are observed between the spectra before and after methylene blue adsorption on biomass. In the case of the spectrum obtained after the adsorption of methylene blue, there is a remarkable change of the intensities of infrared bands with no change positions. The changes in the FTIR spectra, the results confirmed that the process involved is type inclusion of methylene blue with functional groups 
present in the biomass (mechanical entrapment).

\section{CONCLUSION}

The results obtained during the sorption of methylene blue on biomass waste mint show that:

1) The waste mint can be used as good adsorbent particularly for the removal of methylene blue and generally for all dyes.
2) The adsorption isothems could be considered consistent with Langmuir model for initial concentrations: 60,70 and $80 \mathrm{mg} / \mathrm{L}$, and the Freundlich model for initial concentrations: 90 and $100 \mathrm{mg} / \mathrm{L}$.

All the results obtained in this work, we have discovered new ways of valuing the waste mint, giving new biomass in the field of environmental applications.

\section{REFERENCES}

1 Zhu, S. C. ; Miao, C. G. ; Wu, Y. ; Yang, H. X. Advanced Materials Research. 2013, 726, 629-633.

2 Bhatnagar, A. ; Kaczala, F. ; Hogland, W. ; Marques, M. ; Paraskeva, C. A.; Papadakis, V. G. ; Sillanpää, M. Environmental Science and Pollution Research. 2014, 21(1), 268-298.

3. Adinew, B. Bulg J Sci Educ. 2012, 21, 434-456.

4. Carneiro, P. A. ; Umbuzeiro, G. A. ; Oliveira, D. P. ; Zanoni, M. V. B. Journal of Hazardous Materials. 2010, 174(1), 694-699.

5. Verma, A. K. ; Dash, R. R. ; Bhunia, P. A. Journal of Environmental Management. 2012, 93(1), 154-168.

6. Fernando, E. ; Keshavarz, T. ; Kyazze, G. Bioresource technology. 2013, 127, 1-8.

7. Wang, J. L. ; Xu, L. J. Critical Reviews in Environmental Science and Technology. 2012, 42(3), 251-325.

8. Dawood, S. ; Sen, T. K. Water research. 2012, 46(6), 1933-1946.

9. Salleh, M. A. M. ; Mahmoud, D. K. ; Karim, W. A. ; Idris, A. Desalination. 2011, 280(1), 1-13.

10. Fu, F. ; Wang, Q. Journal of Environmental Management. 2011, 92(3), 407-418.

11. Ainane, T. ; Abourriche, A. ; Kabbaj, M. ; Elkouali, M. ; Bennamara, A. ; Charrouf,
M. ; Talbi, M. Journal of Chemical and Pharmaceutical Research. 2014, 6(4), 599606.

12. Fomina, M. ; Gadd, G. M. Bioresource technology. 2014, 160, 3-14.

13. Chowdhury, S. ; Saha, P. D. Applied Water Science. 2012, 2(3), 209-219.

14. Wang, S. ; Zhai, Y. Y. ; Gao, Q. ; Luo, W. J. ; Xia, H. ; Zhou, C. G. Journal of Chemical \& Engineering Data. 2013, 59(1), 39-51.

15. Gupta, V. K. ; Mittal, A. ; Jhare, D. ; Mittal, J. RSC Advances. 2012, 2(22), 8381-8389.

16. Ainane, T. ; Abourriche, A. ; Kabbaj, M. ; Elkouali, M. ; Bennamara, A. ; Charrouf, M. ; Talbi, M. Journal of Materials and Environmental Science. 2014, 5(4), 975-982.

17. Zeng, F. ; He, Y. ; Lian, Z. ; Xu, J. Science of The Total Environment. 2014, 466, 577-585.

18. Hao, S. ; Chu, W. ; Jiang, Q. ; Yu, X. Colloids and Surfaces A: Physicochemical and Engineering Aspects. 2014, 444, 104-113.

19. Sari, A. ; Tuzen, M. Applied Clay Science. 2014, 88, 63-72.

20. Song, X. ; Liu, D. ; Zhang, G. ; Frigon, M. ; Meng, X. ; Li, K. Bioresource technology. 2014, 151, 428-431. 